\title{
Treatment of grain distillation wastewaters in an upflow anaerobic sludge bed (UASB) system
}

\author{
ACJ Laubscher ${ }^{1}$, MC Wentzel $^{2 \star}$, JMW Le Roux ${ }^{1}$ and GA Ekama ${ }^{2}$ \\ 'Stellenbosch Farmers' Winery, PO Box 46, Stellenbosch 7599, South Africa \\ ${ }^{2}$ Water Research Group, Department of Civil Engineering, University of Cape Town, Rondebosch 7701, South Africa
}

\begin{abstract}
In operation of the full-scale upflow anaerobic sludge bed (UASB) system at the Stellenbosch Farmers' Winery (SFW) Wellington distillery, a problem encountered in the treatment of grain distillation wastewater was the accumulation of a floating scum layer. On occasion this was so severe that it forced shutdown of the UASB system to facilitate the physical removal of the scum. A preliminary investigation indicated that the scum-layer behaviour could be replicated at laboratory-scale. Thereafter, two laboratory-scale UASB systems were run in parallel: one (control) receiving wine distillation wastewater as influent, and the other (experimental) grain distillation wastewater at both high and low total suspended solids (TSS) concentrations. Scum-layer accumulation, COD removal and concentration profiles along the axis of flow through the reactors were compared. The scum layer developed only with grain distillation wastewater as influent, and its severity appeared to be linked to the TSS content of the grain wastewater. Reducing the TSS by drum filtration, settling or blending with wine wastewater could reduce, but not eliminate, the scum-layer accumulation. With wine distillation wastewater as influent, concentration profiles exhibited the typical three distinct zones of sludge bed behaviour. However, with grain distillation wastewater as influent, the concentration profiles were markedly different; the three zones of behaviour did not develop. This raises the question of the long-term viability of a UASB system treating grain distillation wastewaters.
\end{abstract}

\section{Introduction}

The upflow anaerobic sludge bed (UASB) system has found wide application in the treatment of industrial wastewaters, particularly those produced in agriculturally based industries (Britz et al., 1999). For example, UASB systems have been successfully applied to treat wastewaters from sugar, potato processing, slaughterhouse, meat packing, paper mill, fruit juicing, food and yeast industries (Lin and Yang, 1991). Also, the UASB system has been shown to be a feasible method for treatment of alcohol distillery effluents (Driessen et al., 1994); COD removal efficiencies in the range of 65 to $95 \%$ can be achieved, depending largely on the kind of raw material used and on the process conditions in the distillery (Driessen et al., 1994). Accordingly, in 1993, the SFW installed a BIOPAQ ${ }^{\circledR}$ UASB reactor at the SFW Wellington Distillery to treat all wastewaters produced in this distillery, before discharge of the treated effluents via the municipal sewer to the local municipal wastewater treatment works. This UASB system consists of two parallel reactors of $150 \mathrm{~m}^{3}$ and $300 \mathrm{~m}^{3}$ respectively and can be operated using either reactor individually, or both reactors simultaneously, at a peak loading of $15 \mathrm{kgCOD} / \mathrm{m}^{3}$ reactor volume/ d (Laubscher et al., 2000)

The UASB system treats a variety of distillery wastewaters, which differ considerably as a result of the different raw materials used in the distillation and/or the distillation process implemented, to produce a variety of end-products. At the SFW Wellington Distillery, both column and pot distillation processes are used. Column distillation is employed in both absolute alcohol $( \pm 96.4 \%$ ethyl alcohol/volume) and grain whisky spirit production. The former uses grape wine as raw material and the wastewater generated is referred to as wine wastewater. The latter uses fermented mash from maize meal $( \pm 9 \% \mathrm{~A} / \mathrm{V})$, called "wort", as raw material and

\footnotetext{
* To whom all correspondence should be addressed. 푱(021) 650-2583; fax: (021) 689-7471; e-mail: markw@eng.uct.ac.za Received 11 November 2000; accepted in revised form 13 June 2001
}

the wastewater generated is referred to as grain wastewater. Pot distillation is used to produce brandy spirit with a superior quality of grape wine (called rebate wine) as raw material; the wastewater generated is also referred to as wine wastewater. Vodka and gin are also produced, but their production is relatively small and contributes negligibly to wastewater production.

All the distillery wastewaters above generally contain high concentrations of organic matter (COD), TSS and protein, particularly the grain wastewater. High TSS content has been found to be detrimental to UASB operation (Fourie, 1974; SRK, 1993). Thus, for distillery wastewaters, usually pretreatment stages are implemented for removal of TSS prior to biological treatment in the UASB system (Fourie, 1974; SRK, 1993). Pretreatment also has been implemented at the SFW Wellington Distillery: The grain wastewater undergoes decanting followed by centrifuging, while the wine wastewater undergoes centrifuging.

When commissioning the UASB system at the SFW Wellington Distillery during the 1995/1996 wine season, several operational problems were encountered. Some of these could be effectively resolved at the treatment plant. However, two major problems could not be resolved - formation of a scum layer when treating grain wastewater, and precipitation of struvite when treating wine wastewater.

With the treatment of grain wastewater, a scum layer accumulated on the liquid surface at the top of the UASB reactors. This scum layer was first observed in November 1995 when the small UASB reactor was fed grain wastewater only. The scum layer manifested as a thick highly viscous gelatinous layer which interfered with effluent overflow at the overflow launders. On occasion, the development of the scum layer was so severe that it forced operational shutdown of the UASB system for physical removal of the layer. The scum-layer formation proved persistent, as it manifested whenever grain wastewater was treated. This operational problem prompted an investigation at laboratory-scale into the treatment of grain distillation wastewater in the UASB 
system. This paper reports on this investigation. The precipitation of struvite was also investigated, and is reported separately by Laubscher et al. (2000).

\section{Preliminary investigation}

Treatment of grain distillation wastewater in a UASB system was investigated using laboratory-scale reactors. To assess whether the scum layer observed at full-scale could be reproduced at laboratoryscale, and validate the experimental protocol, a preliminary investigation was undertaken (Laubscher et al., 2000). In August 1997 a UASB system was set up at laboratory-scale, seeded with granular sludge from the full-scale UASB system. The system was fed grain wastewater obtained from the full-scale plant, after decanting and centrifuging. Also, to assess the effect of TSS concentration on scum-layer formation, grain wastewater that had been batch filtered through a drum filter using filter aid (diatomaceous earth) to remove TSS also served as influent. From this preliminary investigation, the following conclusions could be drawn (for details see Laubscher et al., 2000):

- A scum layer was formed on the liquid surface of the laboratoryscale UASB system, appearing as a thick gelatinous mass, covered by a thin crust. This confirmed that the problem identified at full-scale could be reproduced at laboratory-scale, validating the experimental protocol.

- The scum layer above was present when both the centrifuged (high TSS) and drum filtered (low TSS) grain wastewaters served as influent. However, the scum layer was very much reduced with the filtered grain wastewater compared to the centrifuged grain wastewater. This indicated that the causative agent for the scum layer appeared to be related to the TSS content of the grain wastewater. However, although drum filtering of the wastewater appeared to reduce the problem, it did not eliminate it.

- During periods of successful operation, \% COD removal of $>90 \%$ could be achieved with both the centrifuged and filtered grain wastewater. However, the system was prone to upsets with relatively long recovery periods of about $11 \mathrm{~d}$.

The success in reproducing the scum layer observed at full-scale in the laboratory-scale UASB system prompted a more detailed investigation into this operational problem and the behaviour of the UASB system when treating grain distillation wastewater.

\section{Experimental methods}

\section{Experimental approach}

Two identical laboratory-scale UASB reactors were set up and operated in parallel, one as an experimental unit (Reactor 1) and the other as a control (Reactor 2). Thereafter:

(1) To acclimatise the biomass in both UASB systems and to establish identical performance, both were fed equal quantities and concentrations of wine wastewater as influent.

(2) The control system was maintained on wine wastewater as influent, and the experimental system switched to grain wastewater as influent, fed as a blend with wine wastewater and on its own, at high and low TSS concentrations.

(3) System performance of the experimental and control systems was monitored and compared with respect to scum-layer accumulation, COD removal and concentration profiles of

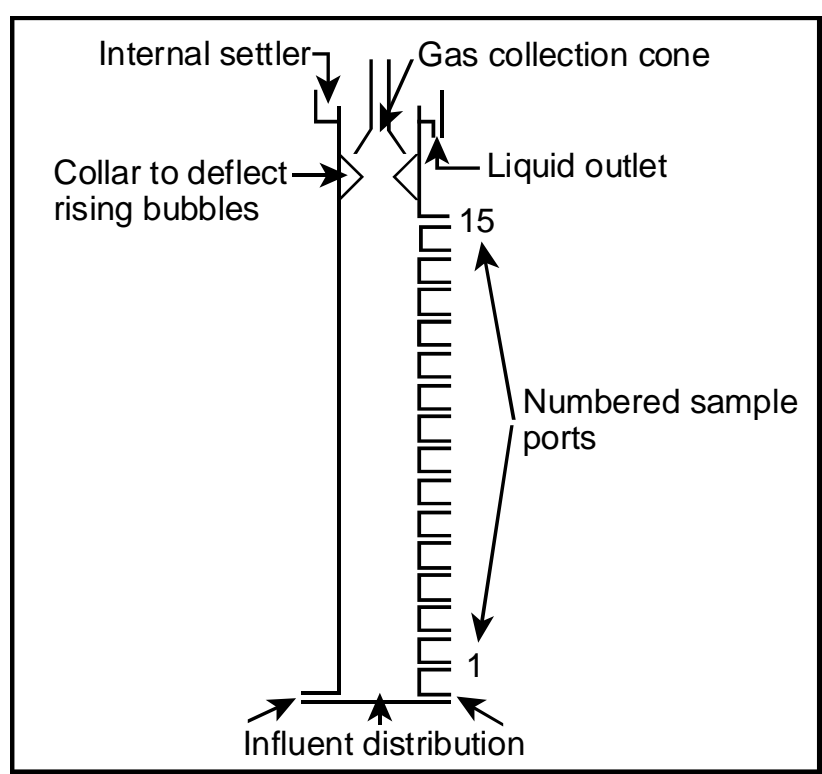

Figure 1

Schematic layout of the laboratory-scale UASB reactor showing the numbered sampling ports

short-chain fatty acids (SCFA), $\mathrm{pH}, \mathrm{COD}$, total soluble phosphorus $\left(\mathrm{P}_{\mathrm{T}}\right)$ and free and saline ammonia (FSA) along the axis of flow through the UASB reactor.

\section{Reactor set-up}

The two laboratory-scale UASB reactors were made from transparent perspex cylinders (Fig. 1), based on the design of SamSoon et al. (1989), but with inside diameter $90 \mathrm{~mm}$ and height 1600 $\mathrm{mm}$, giving a total effective reactor volume of $10.2 \ell$. The reactor bottom was flat with four evenly spaced inlet feed ports discharging in a horizontal direction. At the top of the reactor was the gas/ liquid/solid separator. Gas collection was by means of a hollow inverted cone; rising gas bubbles were defected into the cone by a collar around the inside wall of the reactor below the cone. The gas passed from the cone, along a gas line, through a conical flask which served as a liquid trap, to a wet gas flow meter (Model DM3A, Alexander Wright, London). To prevent channelling in the sludge bed and to ensure free movement of gas out of the sludge bed, the reactor contents were stirred by means of a slow internal stirrer $(2 \mathrm{r} / \mathrm{min})$ driven by a magnetic stirrer motor.

Effluent discharge was via an annular space between the gas collection cone and the reactor wall to enter a small solid/liquid separator (volume approximately $600 \mathrm{~m} \ell$ ). Clarified effluent flowed over a launder (v-shaped weirs) to the collection vessel, while solids which settle out, were returned into the reactor by gravity. Fifteen sampling ports were evenly spaced along the length of the reactor. Temperature in the reactor was maintained at $35^{\circ} \mathrm{C}\left( \pm 1^{\circ} \mathrm{C}\right)$ by a thermostat-controlled electrical heating tape wrapped around the reactor.

The two UASB systems were operated in a flow-through mode with no recycle for alkalinity reuse (Wentzel et al., 1994), since the objective was not to investigate $\mathrm{pH}$ control and the flow-through system is the simplest to operate. 


\begin{tabular}{|c|c|c|c|c|}
\hline \multicolumn{5}{|c|}{$\begin{array}{l}\text { TABLE 1 } \\
\begin{array}{l}\text { Characteristics of the wastewaters used as influent to the laboratory-scale } \\
\text { UASB systems }\end{array}\end{array}$} \\
\hline \multirow[t]{2}{*}{ Wastewater type } & \multicolumn{4}{|c|}{ Wastewater characteristic } \\
\hline & $\begin{array}{l}\text { COD } \\
(\mathrm{mg} / \ell)\end{array}$ & $\begin{array}{c}\mathrm{TKN} \\
(\mathrm{mgN} / \ell)\end{array}$ & $\underset{(\mathrm{mgP} / \ell)}{\mathbf{P}}$ & $\begin{array}{l}\text { TSS } \\
(\mathbf{m g} / \ell)\end{array}$ \\
\hline Wine wastewater after centrifuging & $20000-30000$ & $300-350$ & $180-200$ & $100-500$ \\
\hline $\begin{array}{l}\text { Grain wastewater after decanting and } \\
\text { centrifuging - unsettled }\end{array}$ & $25000-30000$ & $170-180$ & $270-300$ & $>1000$ \\
\hline $\begin{array}{l}\text { Grain wastewater after decanting, } \\
\text { centrifuging and settling }\end{array}$ & $20000-25000$ & $170-180$ & $270-300$ & $<1000$ \\
\hline
\end{tabular}

\section{Wastewater characteristics}

The influent feed stock was of three types:

- Wine wastewater.

- Unsettled grain wastewater.

- Settled grain wastewater.

The wine and unsettled grain wastewater were those fed to the fullscale system. The grain wastewater was collected after the decanting and centrifugation pretreatment stages and the wine wastewater after centrifugation (see above). The wastewaters were transported to the laboratory and stored in a refrigerated room at $4^{\circ} \mathrm{C}$.

For the grain wastewater, to investigate the effects of the TSS content of this wastewater on scum-layer accumulation, a grain wastewater with high $(>1000 \mathrm{mg} / \ell)$ and low $(<1000 \mathrm{mg} / \ell)$ TSS content was used as influent feed to the experimental UASB system (Reactor 1). The decanted and centrifuged grain wastewater with TSS $>1000 \mathrm{mg} / \ell$ served as the high TSS grain wastewater feed, termed "unsettled grain wastewater". For the low TSS content grain wastewater, in the preliminary investigation, the grain wastewater was drum-filtered to reduce the TSS. However, drum filtration proved impractical at large scale, because of the batch method of operation. Accordingly, drum filtration had been terminated and could not be used to produce low TSS grain wastewater for this part of the investigation. Experiments indicated that extended settling $(>2 \mathrm{~d})$ reduced the TSS content of the grain wastewater to $<1000 \mathrm{mg} / \ell$. Accordingly, to produce low TSS grain wastewater, the grain wastewater was settled for $3 \mathrm{~d}$ and the supernatant decanted to serve as influent feed, termed "settled grain wastewater". The characteristics of the wastewaters are listed in Table 1.

The daily feed to the two laboratory-scale UASB reactors was drawn from the appropriate concentrated feed stock, and diluted with tap water to a COD concentration of 3000 to $5000 \mathrm{mg} / \ell$. This concentration was selected according to Sam-Soon et al. (1990); for flow-through systems, dilution of the influent COD into the range 2000 to $5000 \mathrm{mgCOD} / \ell$ provides more stable operation. Furthermore, this COD concentration approximates the influent COD concentration that would be achieved in practice with typical recycle ratios (from effluent to influent) that would be implemented for this wastewater for alkalinity reuse (Wentzel et al., 1994). Where the experimental and control systems received the same influent, this was made up together and divided between the two systems.
The $\mathrm{pHs}$ of all three wastewater types were low, $\mathrm{pH} 4.0$ to 4.5 . The flow-through mode of the UASB operation selected, and the production of short-chain fatty acids in the lower part of the UASB reactor will cause the $\mathrm{pH}$ to remain low (Sam Soon et al., 1989). This low $\mathrm{pH}$ will inhibit methanogenesis $(\mathrm{pH}<6.8$, Wentzel et al., 1994). Accordingly, alkalinity was added to the influent in the form of 100 to $200 \mathrm{mg} \mathrm{NaHCO}_{3}$ per $20 \ell$ diluted feed. This caused the $\mathrm{pH}$ in the UASB reactor sludge bed to stabilise at about 7 . Furthermore, no trace metals were added to the feed, as these would be present in adequate quantity.

\section{Analytical methods}

The following parameters were measured daily to assess the reactor performance:

- COD, unfiltered influent and effluent

- $\mathrm{pH}$ in influent and settler

- Gas production

- Influent flow rate.

Additionally, during the third experimental period (see below), the following were measured:

- Effluent short-chain fatty acids (SCFA)

- Effluent $\mathrm{H}_{2} \mathrm{CO}_{3}^{*}$ alkalinity

- Individual SCFA, pH, COD, free and saline ammonia (FSA) and total soluble phosphorus $\left(\mathrm{P}_{\mathrm{T}}\right)$ profiles from the 15 sampling ports along the length of the reactors.

CODs and FSAs were measured in accordance with Standard Methods (1985). Total soluble phosphorus was measured on $0.45 \mu \mathrm{m}$ filtered samples using persulphate digestion, followed by molybdate vanadate colorimetric reaction (Standard Methods, 1985). Gas production was measured by means of a wet gas meter (model No. DM3A, Alexander Wright, London). The $\mathrm{pH}$ was measured with a portable Hanna pH meter (HI 9025) fitted with an epoxy-combined pHelectrode (Hanna HI 1230). SCFA and $\mathrm{H}_{2} \mathrm{CO}_{3}{ }^{*}$ alkalinity were measured with the 5-point titration method (Moosbrugger et al., 1992). Individual SCFA species were determined by gas chromatography using a Varian Model 3700 gas chromatograph equipped with a flame ionisation detector (FID) and a Nukol ${ }^{\mathrm{TM}}$ fused silica capillary column $(30 \mathrm{x} 0.53 \mathrm{~mm}$ in diameter and $0.5 \mu \mathrm{m}$ film thickness) (Supelco, Inc., Bellefonte). 


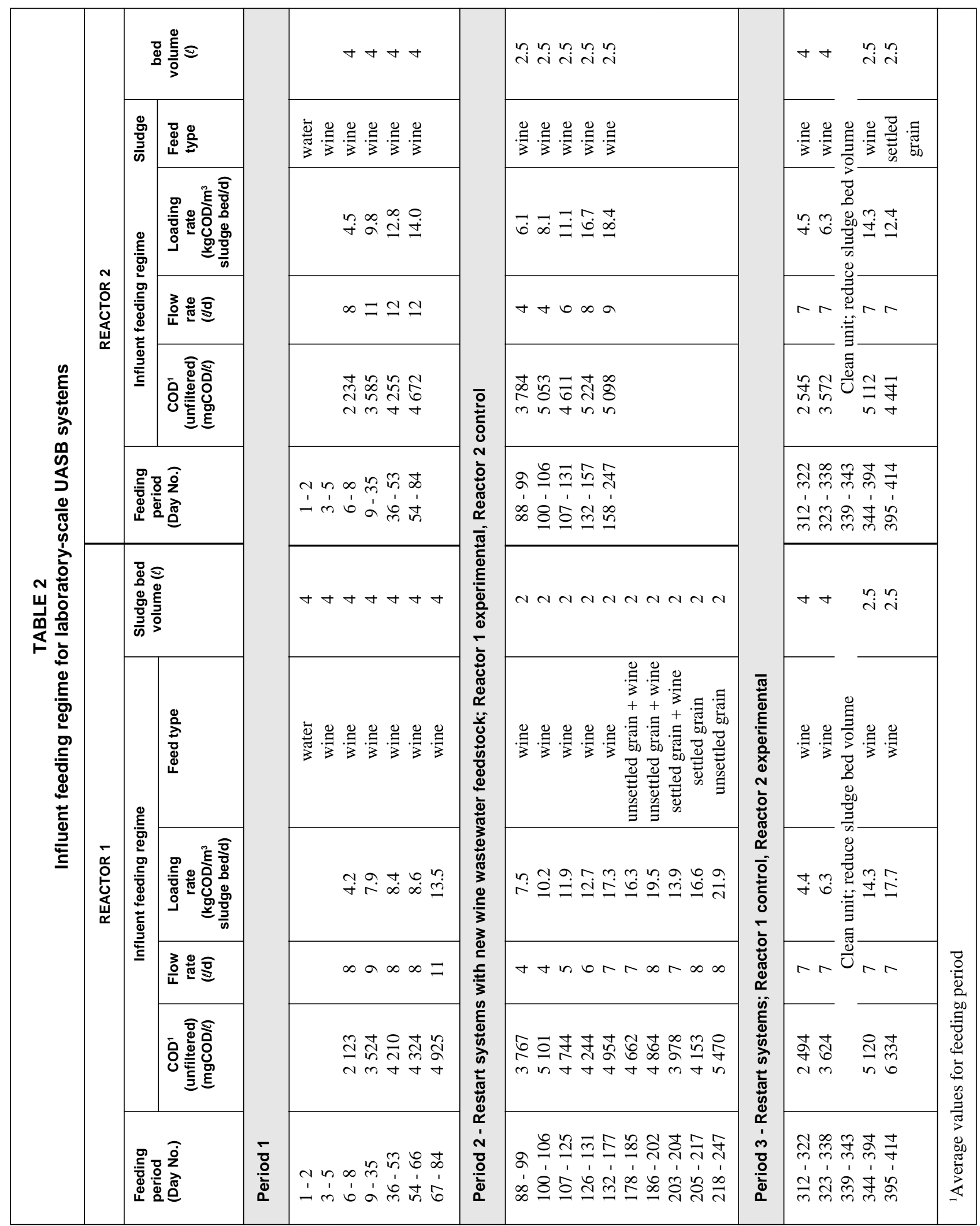


Calibration was with a solution of acetic, propionic, i-butyric, n-butyric, i-valeric and n-valeric acids added to $0.5 \mathrm{~m} \ell 0.1 \mathrm{~N} \mathrm{HCl}$ with an internal standard of n-hexanol (26\%). The internal standard was chosen because its polarity and boiling point allowed it to be closest to the fatty acid peaks.

For the profiles, samples were drawn from the ports down the reactors by means of a special device that allowed the sample to be extracted and the $\mathrm{pH}$ measured without loss of dissolved gases, particularly $\mathrm{CO}_{2}$. Loss of $\mathrm{CO}_{2}$ causes change in $\mathrm{pH}$ but does not influence alkalinity (Loewenthal et al., 1989).

\section{Experimental periods and system operation}

Table 2 shows the feeding regime and loading rates implemented over the entire study which extended over $414 \mathrm{~d}$. Three distinct periods of operation were identified, and are described separately below.

\section{Period 1}

Granular anaerobic sludge from the fullscale UASB reactor at the Wellington Distillery was used to seed the two laboratory-scale UASB systems with approximately $4 \ell$ of sludge each. Prior to seeding, the sludge was rinsed with tap water in order to remove dead debris and fine particles, and the seed sludge contained well-structured granules, 1 to $2 \mathrm{~mm}$ in diameter. The operating temperature was set at $35^{\circ} \mathrm{C}\left( \pm 1^{\circ} \mathrm{C}\right)$.

For the first $48 \mathrm{~h}$, only water was fed to the reactors, to ensure that any formation of a scum layer in the laboratory-scale units was not simply because of a carryover from the full-scale system. On the third day low concentrations of diluted wine wastewater were fed to both reactors for the next $3 \mathrm{~d}$ and thereafter, the COD loading rates were gradually increased (see Table 2).

The first objective was to continue feeding both units with diluted wine waste until $>90 \%$ COD removal efficiencies were attained, indicating that the biomass had fully acclimatised (SamSoon et al., 1989). However, the COD removal in both units remained poor, decreasing to well below $50 \%$ for both units by Day 84 when the Period 1 investigation was terminated. A definitive explanation for the poor COD removal behaviour of the UASB systems could not be identified at that stage. However, from results obtained during Period 2 (see below), it was concluded that the poor reactor performance was related to the wine wastewater "stock" used as feed during Period 1 - when "new" wine wastewater was collected from the distillery and fed to the units only $3 \mathrm{~d}$ after termination of Period 1, the laboratory-scale units immediately showed vastly improved COD removal, $>90 \%$ within one week.

\section{Period 2}

\section{Start-up}

Period 2 commenced on Day 88 with "new" wine wastewater and reduced sludge volumes. The sludge beds in the reactors were drained to about 2.0 and $2.5 \ell$ for Reactors 1 and 2 respectively. To acclimatise the sludge, diluted wine wastewater initially was fed to both units, at a COD of about $3800 \mathrm{mg} / \ell$ (Table 2). The flow rate was set at $4 \ell$ per day for both units, i.e. COD loading rate of 7.5 and $6.1 \mathrm{kgCOD} / \mathrm{m}^{3}$ sludge $\cdot \mathrm{d}$ for Reactors 1 and 2 respectively. (In order to have a "standard" reference, all organic loading rates will be expressed in terms of mass of substrate fed per day per unit sludge bed volume - this eliminates variations in "dead" volume above the sludge bed). The loading rate was kept constant for both reactors and after one week COD removal efficiencies of $90 \%$ were obtained. This indicated that the sludge beds in both units were fully acclimatised to the wine wastewater.

\section{Loading rate}

For Period 2, loading rates for Reactors 1 and 2 are shown in Fig. 2. With wine wastewater as influent feed to both reactors, the loading rates were gradually increased from the initial loading rates to about $18 \mathrm{kgCOD} / \mathrm{m}^{3}$ sludge $\cdot \mathrm{d}$ by Day 177 . This enabled the feed type to the experimental system to be changed.

\section{Substrate feed}

During Period 2, the main objective was to implement substrate changes to the experimental unit (Reactor 1) and compare its performance with the control unit (Reactor 2), see Table 2. Accordingly, the feed to the experimental reactor was changed from wine wastewater to a 1:1 blend of unsettled grain and wine 


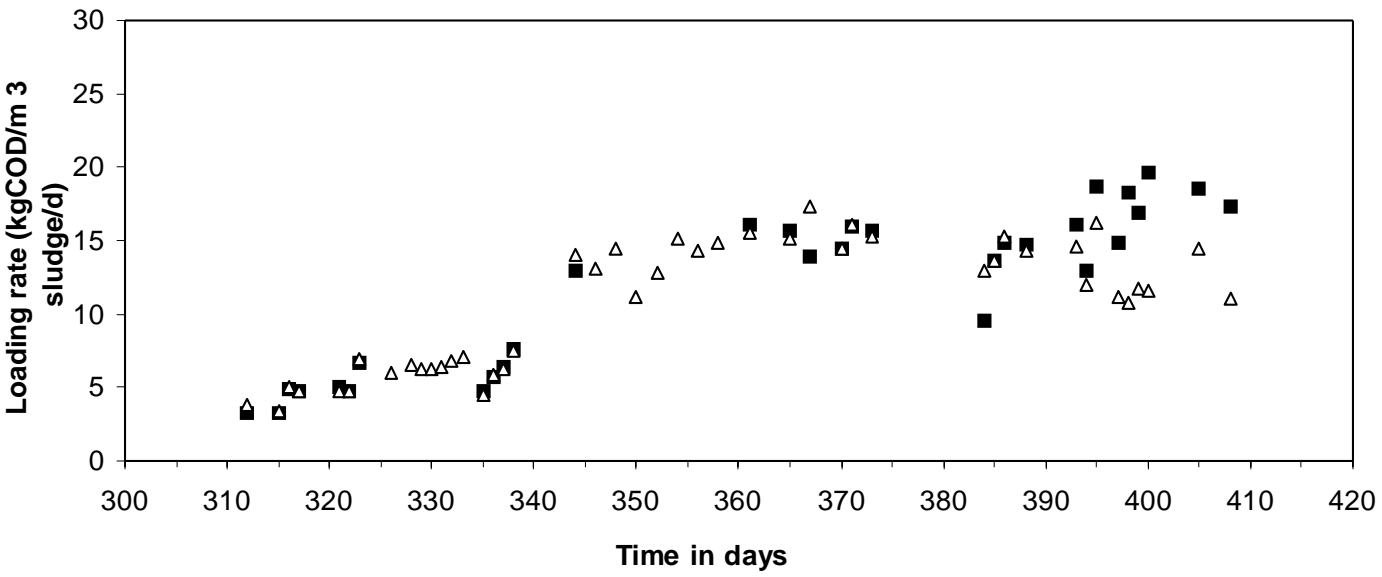

- reactor $1 \quad \Delta$ reactor 2

wastewaters on Day 178, then to a 1:1 blend of settled grain and wine wastewater on Day 203, and, thereafter, to only settled grain wastewater on Day 205. On Day 218 the final feed change was made and only unsettled grain wastewater was fed until the termination of Period 2 on Day 247.

\section{Period 3}

Period 3 commenced after a shutdown for $64 \mathrm{~d}$. Once it was established in Period 2 that scum-layer accumulation is a phenomenon common to the treatment of any type of the grain wastewater (centrifuged, filtered, settled, or blended), UASB reactor behaviour when treating grain wastewater compared with the behaviour when treating wine wastewater was examined in more detail. This involved comparing the concentration profiles along the line of flow of the UASB reactor when treating grain and wine wastewaters.

\section{Start-up}

Period 3 commenced on Day 312 with the following changes. Reactor 1, operated as the experimental unit during Period 2, was operated as the control unit and vice versa. "New" sludge was collected from the full-scale UASB system. In the control unit (Reactor 1), $4 \ell$ of the "new" sludge was used to replace the sludge from Period 2, because during Period 2 this unit had received grain wastewater and both systems were to be started on wine wastewater. Some "new" sludge was also added to the experimental unit (Reactor 2), to increase the volume to $4 \ell$. This unit had only received wine wastewater during Period 2 and so the existing sludge bed did not need to be replaced. The same wine wastewater that served as influent during the Period 2 was used as substrate feed. Diluted wine wastewater was fed to both units to acclimatise the seeding sludges, at initial loading rates of about $4.5 \mathrm{kgCOD} / \mathrm{m}^{3}$ sludge $\cdot d$ for both reactors (see Table 2).

\section{Loading rates}

Figure 4 shows COD loading versus time for Reactors 1 and 2 respectively over Period 3 . The loading rates were gradually increased to $6.3 \mathrm{kgCOD} / \mathrm{m}^{3}$ sludge $\cdot \mathrm{d}$ before both units were shut down for $1 \mathrm{~d}$ on Day 338 and cleaned. Sludge from both units was drained leaving a balance of about $2.5 \ell$. Thereafter, the loading rates were immediately increased to $14.3 \mathrm{kgCOD} / \mathrm{m}^{3}$ sludge $\cdot \mathrm{d}$ for both units. On Day 395 the feed to the experimental unit (Reactor 2) was changed to settled grain wastewater (see above).

\section{Results and discussion}

\section{Period 2}

\section{Sludge bed changes}

The level of the sludge bed could be monitored through the transparent wall of the two reactors, and stayed reasonably stable in both reactors throughout the investigation, at approximately $1 / 2$ the reactor volume. Sludge granule size remained approximately constant, at a diameter of 1 to $2 \mathrm{~mm}$. Dead pellet debris washout was observed, but this is common in UASB systems. In the experimental reactor (Reactor 1 ), when it received grain wastewater as influent this pellet debris became entrapped in the scum layer that formed on the liquid surface (see below).

With the grain wastewater, the fine grain particles suspended in the feed flocculated as distinct yellowish flocs when the $\mathrm{pH}$ was increased to near neutral by $\mathrm{NaHCO}_{3}$ addition, particularly in the unsettled feed. These particles tended to be captured in the experimental reactor sludge bed and did not seem to biodegrade readily. Eventually the sludge bed in this reactor became saturated with fine grain particles giving the sludge bed a yellowish appearance. These yellowish particles were also washed out of the sludge bed, and were entrapped in the scum layer which formed on top of the reactor (see below). Further, in the experimental reactor, when receiving grain wastewater as influen, $t$ there was always a thin layer $( \pm 5 \mathrm{~mm})$ of fine gelatinous sludge visible on top of the sludge bed, which continuously formed and was washed out to the effluent.

\section{System performance}

In Fig. 2 COD loading and in Fig. 3 COD removal vs. time are shown for Reactors 1 and 2 during Period 2. In Table 2, the substrate feed types and loading rates applied are shown. For the first $90 \mathrm{~d}$ the influent feed was wine wastewater. From Fig. 3, within $8 \mathrm{~d}$ of start up (Day 95) Reactor 1 achieved COD removals $>90 \%$ and these removals were maintained throughout the investigation. For Reactor 2, initially COD removals were variable due to problems in operation of the laboratory-scale system, but after about $60 \mathrm{~d}$ (Day 148) removals $>90 \%$ were achieved and maintained for the rest of the investigation. This indicated that the sludge masses were fully acclimatised to the operating conditions. Also, both systems were able to successfully accommodate the increase in loading rate (see Fig. 2) without deterioration in effluent quality. Accordingly, the substrate changes above were implemented for Reactor 1 (see Table 2). For Reactor 1, removals $>90 \%$ were 


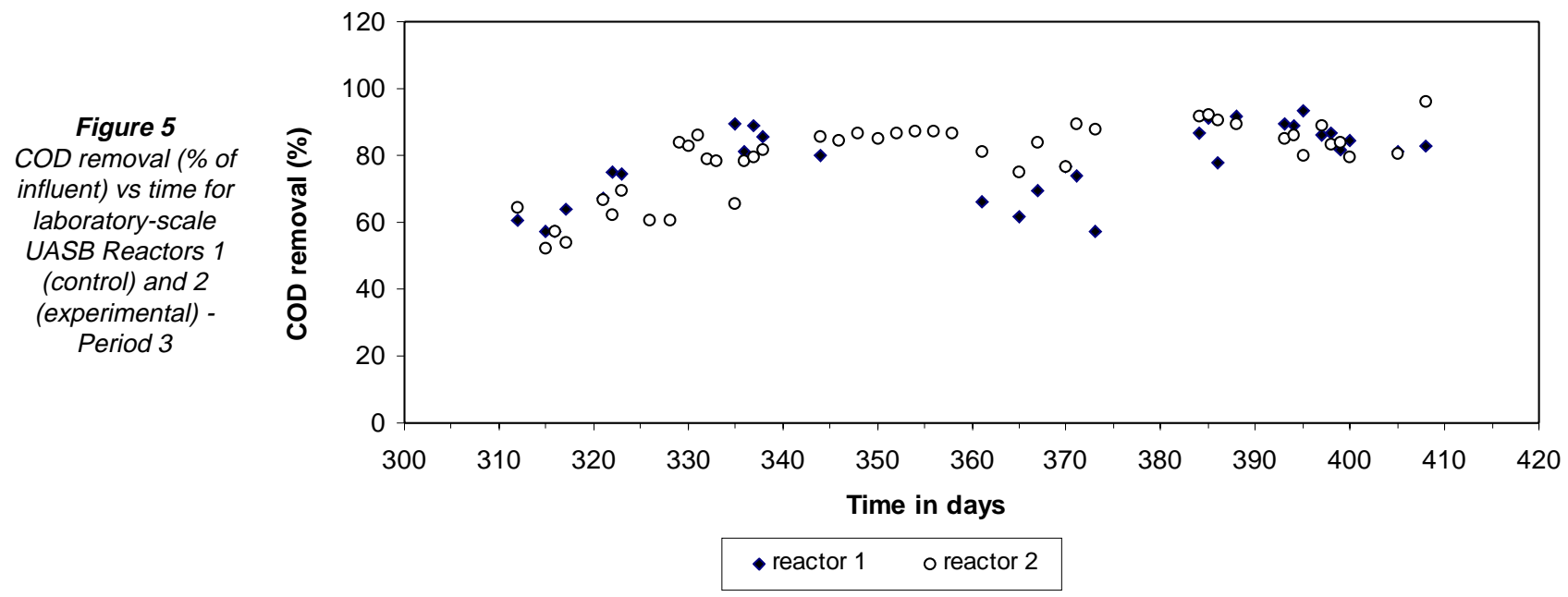

achieved with influent feed of wine wastewater, 1:1 blend of wine and unsettled grain wastewater and settled and unsettled grain wastewater only (see Fig. 3). Furthermore, following a substrate change, no deterioration in system performance was observed. These observations confirmed the conclusions from the preliminary investigation, that with an existing sludge bed, system performance with grain wastewater in all forms is good. Also, very little or no adaptation is necessary in switching from one feed type to the other.

These results appeared to indicate that grain wastewater can be treated successfully in the UASB system, provided scum-layer accumulation (see below) can be accommodated and an existing granular sludge bed is available.

\section{Scum-layer formation}

The formation of the scum layer was determined visually. With the wine wastewater, scum-layer accumulation was never observed. However, with the grain wastewater in any form, i.e. blend, settled or unsettled, the scum layer accumulated; if physically removed, the layer redeveloped within $24 \mathrm{~h}$. These observations confirm that the scum-layer accumulation is a property of the grain wastewater and not distillery wastewaters in general.

The scum layer appeared as a thick gelatinous layer containing debris particles, dead granular sludge and fine particles, which tended to be extremely sticky and oily, covered by a thin crust. Microscopic examination (Britz, 1998) indicated in the crust layer the presence of a long rod-shaped motile organism with point flagella using a "spin-turn" action for movement, and in the oily layer a number of filamentous type bacteria.

The thickness of the scum layer was found to depend on the substrate feed composition, and was not a consequence of biomass changes or reactor performance. The scum-layer accumulation was most severe with the unsettled grain wastewater, and reduced in the blend and settled grain wastewaters. This confirmed the findings in preliminary investigation, that the scum-layer accumulation was linked to the solids content of the grain wastewater. However, blending the grain wastewater with wine wastewater, or settling the grain wastewater reduced, but did not prevent scumlayer accumulation. This is in agreement with the results on the drum-filtered grain wastewater (see Preliminary investigation). Therefore, settling or drum filtering the grain wastewater prior to treatment in the UASB system can reduce, but not eliminate, the scum layer.

\section{Period 3}

\section{System performance}

In Fig. 4 COD loading and in Fig. 5 COD removal vs. time for Reactors 1 (control) and 2 (experimental) are shown for Period 3. In Table 2, the substrate feed types and loading rates applied are shown. From Table 2, for the first $27 \mathrm{~d}$ the influent feed was wine wastewater. From Fig. 5, during this time both UASB systems achieved COD removals of $>80 \%$. On Day 339, the units were stopped for cleaning, and the sludge in each unit was drained to an effective volume of $2.5 \ell$. On Day 344, both reactors were restarted on wine wastewater again at higher loading rates (see Fig. 4). From Fig. 5 it can be seen that the COD removals in both systems remained $>80 \%$. However, on Day 360 COD removals decreased due to some unidentified problem, but thereafter increased to > $80 \%$ by Day 384 , and remained $>80 \%$ in both reactors for the rest of the investigation, to Day 414.

Figures 6 and 7 show the effluent SCFA concentrations and $\mathrm{H}_{2} \mathrm{CO}_{3} *$ alkalinity concentrations respectively for Reactors 1 and 2, for the period from Day 393 to Day 400. From Fig. 6 it is evident that the effluent SCFA concentrations for Reactor 2 (experimental) decreased when this reactor was switched from wine wastewater to settled grain wastewater, from 200 to $400 \mathrm{mg} / \ell$ as HAc to values as low as $0 \mathrm{mg} / \ell$ as HAc. Figure 7 shows that the effluent $\mathrm{H}_{2} \mathrm{CO}_{3}{ }^{*}$ alkalinity for Reactor 2 treating settled grain wastewater was initially lower than Reactor 1 treating wine wastewater, but increased as the sludge adapted to the settled grain wastewater.

With regard to the effluent SCFA, the reduction in concentration on switching from wine wastewater to settled grain wastewater indicates a notable change in behaviour. This is confirmed and dealt with in more detail when comparing the bed profiles with the two wastewaters (see below).

\section{Concentration profiles}

Figures 8(a, b, c, d and e) show concentration profiles taken on Day 408 along the length of Reactors 1 and 2 respectively for $\mathrm{pH}, \mathrm{COD}$, FSA, $\mathrm{P}_{\mathrm{T}}$ and SCFA species concentrations. On this day Reactor 1 treated wine wastewater and Reactor 2 treated settled grain wastewater.

With regard to the profiles measured with wine wastewater, these conform to profiles measured previously with apple juice wastewater (Sam-Soon et al., 1987), glucose (Sam-Soon et al., 1990), protein (Moosbrugger et al., 1990), brewery wastewater (Moosbrugger et al., 1993a) and wine distillery wastewater (Moosbrugger et al., 1993b): 
Figure 6

Effluent total short-chain fatty acid (SCFA) concentrations for laboratory-scale UASB

Reactors 1 (control) and 2 (experimental) - Period 3.

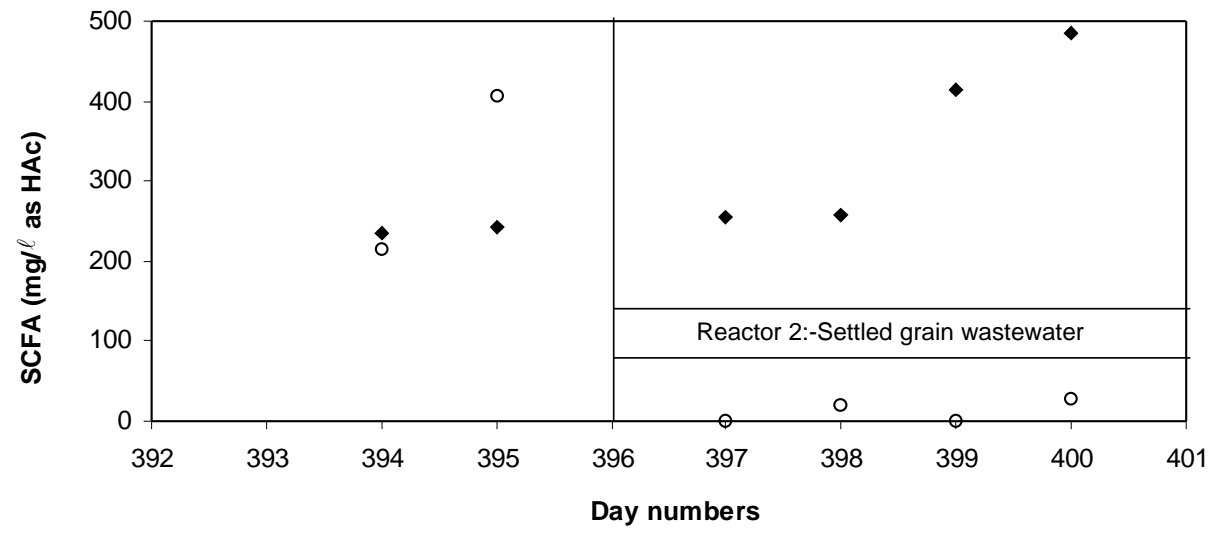

Figure 7

Effluent $\mathrm{H}_{2} \mathrm{CO}_{3}{ }^{*}$ alkalinity concentrations for laboratoryscale UASB Reactors 1 (control) and 2 (experimental) - Period 3.

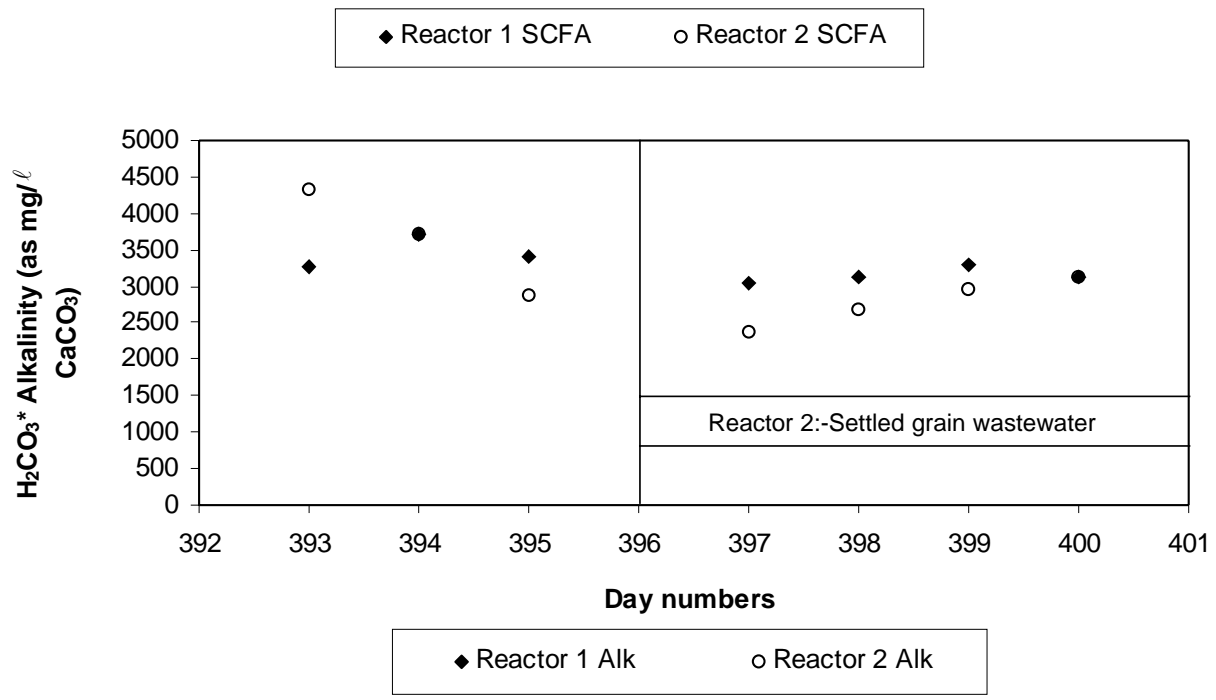

Free and saline ammonia (FSA): From Fig. 8(d), FSA initially increases to reach about $195 \mathrm{mgN} / \ell$ at Port 2 , due to deamination of organic $\mathrm{N}$ present in the influent. Thereafter, FSA exhibits a decrease to reach a minimum of about $155 \mathrm{mgN} / \ell$ through the rest of the bed, due to uptake of FSA for cell and pellet polymer synthesis.

Soluble phosphorus: From Fig. 8(e) phosphorus exhibits only a small decrease through the sludge bed, due to the uptake for cell synthesis.

As noted earlier, this behaviour conforms to that observed by SamSoon and co-workers. To explain the behaviour, they proposed that three distinct zones be identified (Wentzel et al., 1994):

- A lower active zone in which concentrations of the SCFAs, $\mathrm{HAc}$ and $\mathrm{HPr}$, increase to maxima, soluble COD reduces to less than half its influent value, and $\mathrm{pH}$ declines to a minima - Ports 0 to 2 here.

HAc: From Fig. 8(c), HAc increases in the lower part of the sludge bed to reach a maximum of about $950 \mathrm{mgHAc} / \mathrm{l}$ by Port 2 . Thereafter, HAc decreases to reach about $100 \mathrm{mgHAc} / \mathrm{l}$ by Port 5 , and remains at approximately this value through the rest of the sludge bed.

HPr: From Fig 8(c), HPr conforms to the HAc profile, reaching a maximum of approximately $950 \mathrm{mgHPr} / \ell$ in the lower part of the sludge bed and decreasing to a minimum of $150 \mathrm{mgHPr} / \ell$ in the top part of the sludge bed. 
Figure 8(a)

Comparison of $\mathrm{pH}$ profiles along the line of flow through laboratoryscale UASB systems treating wine wastewater (Reactor 1) and grain wastewater (Reactor 2) - Period 3. a

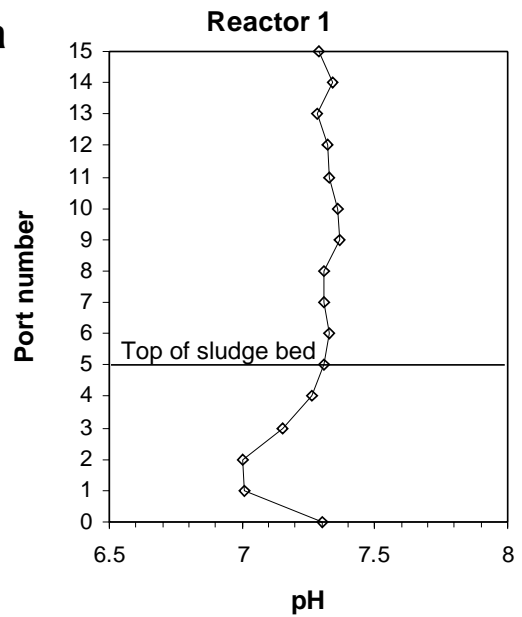

b

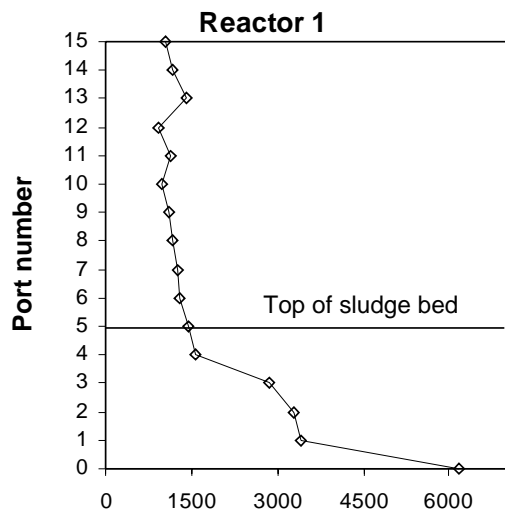

Filtered $\operatorname{COD}(\mathbf{m g} / \ell)$

C

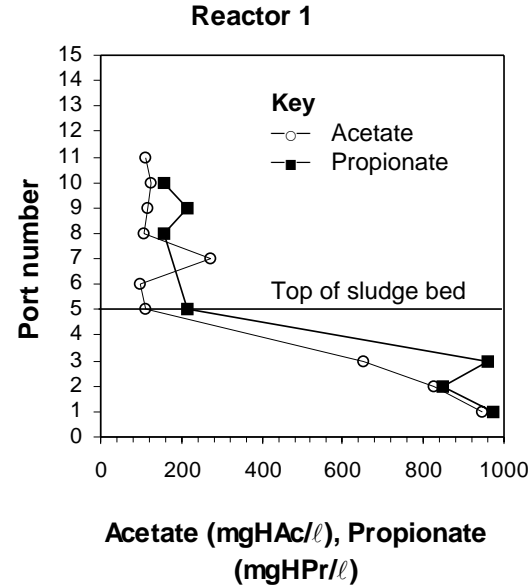

$(\mathrm{mgHPr} / \ell)$
Reactor 2

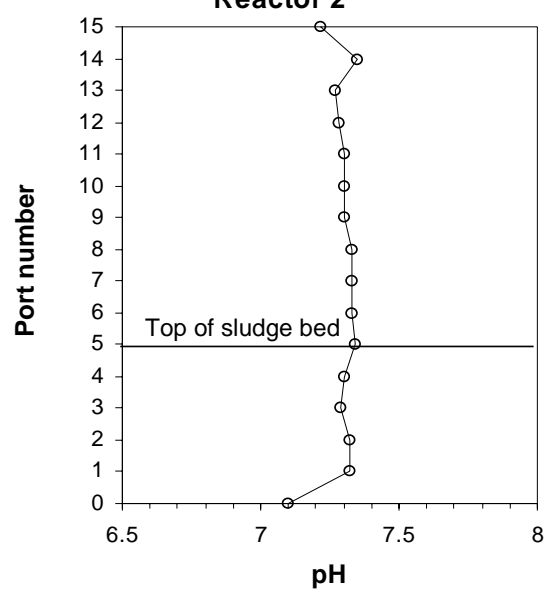

Reactor 2

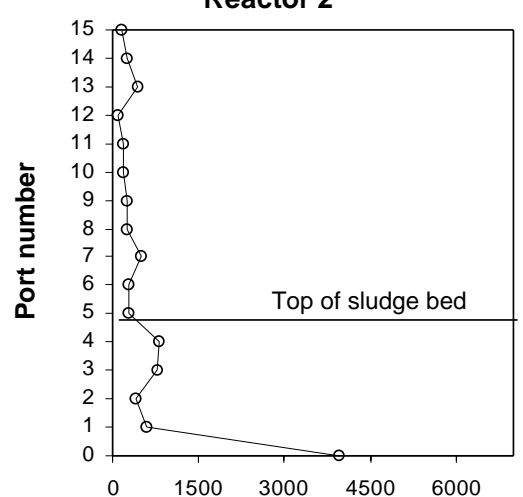

Filtered COD $(\mathbf{m g} / \ell)$

Reactor 2

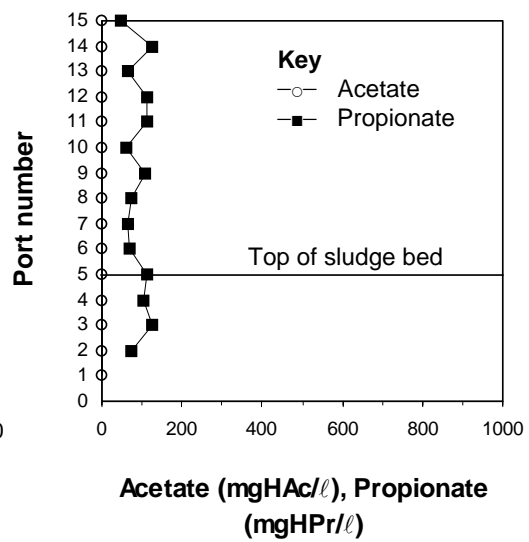

Comparison of acetic ( $H A C$ ) and propionic (HPr) acid concentration profiles along the line of flow through laboratoryscale UASB systems treating wine wastewater (Reactor 1) and grain wastewater (Reactor 2) Period 3.

- In the lower active zone-Acidogens generate SCFA, principally acetic (HAc) and propionic ( $\mathrm{HPr})$, carbon dioxide $\left(\mathrm{CO}_{2}\right)$ and hydrogen $\left(\mathrm{H}_{2}\right)$ from the influent substrate. The hydrogen is generated at such a rate that a high hydrogen partial pressure (high $\left.p \mathrm{H}_{2}\right)$ is created. This is indicated by the observed increase in $\mathrm{HPr}$ which is produced only under high $p \mathrm{H}_{2}\left(>10^{-3.7} \mathrm{~atm}\right)$; Hydrogenotrophic methanogens generate methane $\left(\mathrm{CH}_{4}\right)$ from $\mathrm{H}_{2}$ and $\mathrm{CO}_{2}$; Acetoclastic methanogens convert some $\mathrm{HAc}$ to $\mathrm{CH}_{4}$ and $\mathrm{CO}_{2}$; Acetogens are inactive due to the high $p \mathrm{H}_{2}$.

- In the upper active zone - The $p \mathrm{H}_{2}$ has been reduced to, and maintained at, such low values due to action of hydrogenotrophs that: Acetogens can convert $\mathrm{HPr}$ to $\mathrm{HAc}, \mathrm{H}_{2}$ and $\mathrm{CO}_{2}$; Acetoclastic methanogens convert all the $\mathrm{HAc}$ to $\mathrm{CH}_{4}$ and $\mathrm{CO}_{2}$.
- In the upper inactive zone - No observable biological activity takes place.

From the above, it is apparent that the differentiation of the sludge bed into lower and upper active zones is based on whether HPr generation takes place (lower active, high $p \mathrm{H}_{2}$ ) and whether $\mathrm{HPr}$ oxidation to HAc occurs (upper active, low $p \mathrm{H}_{2}$ ) or not (lower active, high $p \mathrm{H}_{2}$ ); HPr is generated by acidogens only under high $p \mathrm{H}_{2}$ and oxidised to HAc by acetogens only under low $p \mathrm{H}_{2}$.

From the observations made here, these proposals apply also to the UASB system treating wine wastewater. However, the profiles for the UASB system treating grain wastewater differ markedly from those for the UASB system treating wine wastewater: 
d

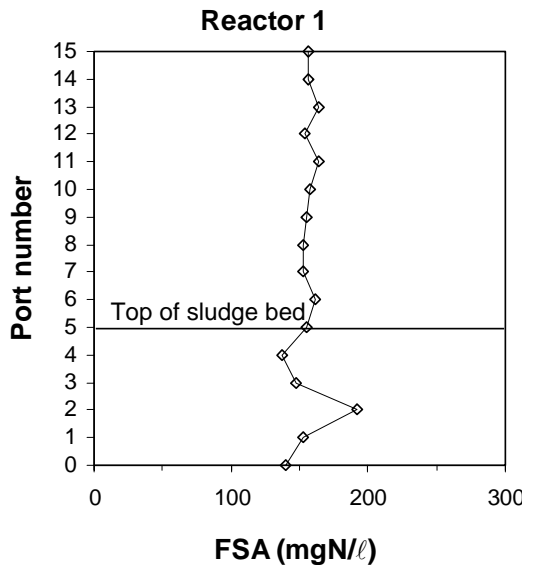

Comparison of free and saline ammonia (FSA) concentration profiles along the line of flow through laboratory-scale UASB systems treating wine wastewater (Reactor 1) and grain wastewater (Reactor 2) - Period 3.

\section{Figure 8(e) \\ Comparison of total soluble phosphorus concentration profiles along the line of flow through laboratory-scale UASB systems treating wine wastewater (Reactor 1) and grain wastewater (Reactor 2) - Period 3.}

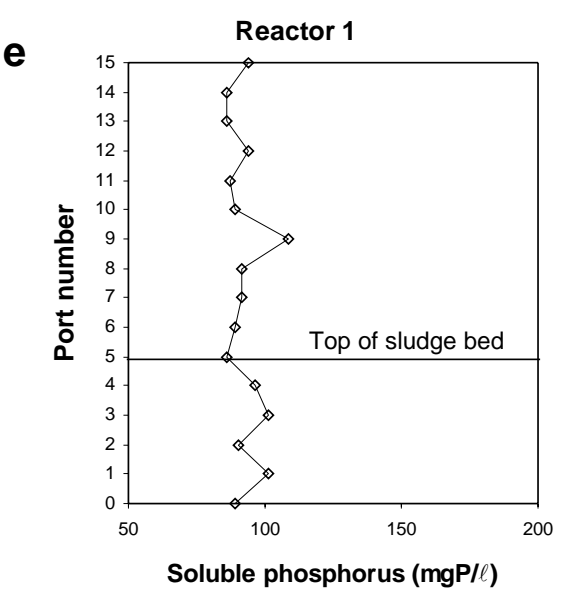

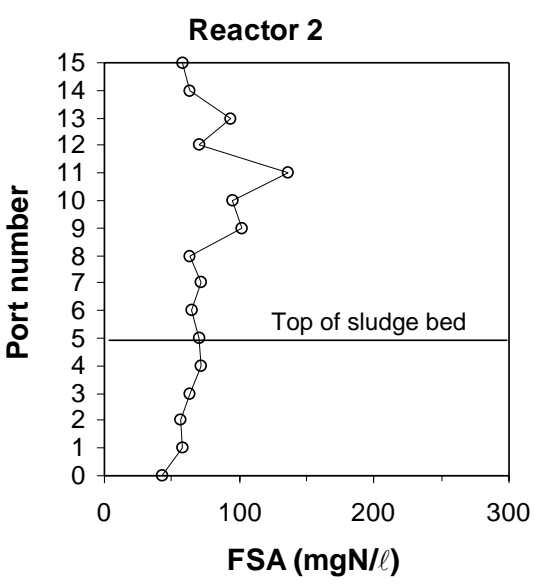

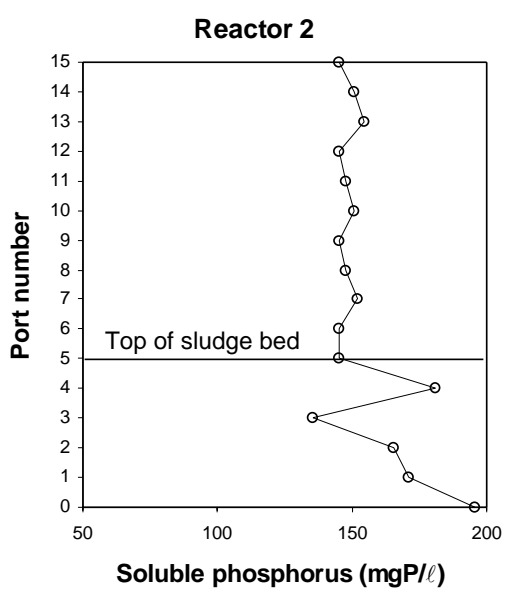

pH: From Fig. 8(a), the pH profile does not exhibit the characteristic decrease in the lower part of the sludge bed followed by an increase in the upper part of the bed, but remains approximately constant at $\mathrm{pH}=7.34$ throughout the sludge bed.

COD: From Fig. 8(b), the COD decreases from the influent value of $3960 \mathrm{mgCOD} / \ell$ to about $600 \mathrm{mgCOD} / \ell$ at Port 1 , and thereafter decreases slowly to about $280 \mathrm{mgCOD} / \ell$ by Port 5 and remains at this value throughout the rest of the sludge bed.

HAc: From Fig. 8(c), negligible HAc were measured throughout the sludge bed. This conforms with measurements made on effluent samples, see above.

HPr: From Fig. 8(c), the HPr is constant through the sludge bed at a low value of about $80 \mathrm{mgHPr} / \ell$.

FSA: From Fig. 8(d), the FSA shows a slight increase through the sludge bed, probably due to deamination of organic-N.

Soluble phosphorus: From Fig. 8(e), soluble phosphorus shows a small decrease through the sludge bed, due to uptake for cell synthesis.

The profile for the UASB system treating grain wastewater indicates that with this wastewater the three zones of behaviour identified for the system treating wine wastewater (and similar wastewaters, Wentzel et al., 1994) do not develop to any marked extent. A possible explanation for this is that the grain wastewater contains considerable suspended solids. The rate of acidogenesis with suspended solids as substrate would be limited by the rate of hydrolysis. Typically, hydrolysis rates would be much slower than acidogenesis rates with a soluble substrate. The net effect is to lower the overall rate of acidogenesis. With the lower acidogenic rates, the short chain-fatty acids would be consumed in subsequent reactions as they are produced. Also, the low rate of acidogenesis implies that the rate of $\mathrm{H}_{2}$ production is low, so that a high $p \mathrm{H}_{2}$ zone does not develop in the sludge bed.

With grain wastewater, the absence of a differentiation into the three zones of behaviour raises the question of the long-term viability of a UASB system treating this type of wastewater. In developing their hypothesis for pelletisation in UASB systems, Sam-Soon et al. (1987) proposed that partial phase separation of the anaerobic processes and development of a zone with a high $p \mathrm{H}_{2}$ were essential for pellet formation (Wentzel et al., 1994). In the UASB system treating grain wastewater, observations (no HAc and little HPr) indicate that these prerequisites for pellet formation are not achieved. If this is true, according to the hypothesis of SamSoon et al. (1987), pellet growth will not occur, or it will be greatly reduced. This indicates that, in the long term in switching from wine wastewater (where pellet growth has occurred) to grain wastewater there will be a gradual loss of the pelletised sludge bed, until it declines to such low values that the system will fail. It is probable that the laboratory-scale systems receiving grain wastewater were not operated for periods long enough for the loss in sludge bed to be noticeable. Some loss of pelletised bed was observed, with pellet debris accumulating in the scum layer on the liquid surface, but pellet break-up and loss are common in UASB systems. The systems would have to be operated for longer periods to determine whether the sludge bed loss is significant, and whether the sludge bed lost can be regenerated. 
The investigation indicates that when switching from wine wastewater, where a well-defined pelletised sludge bed has been developed, to grain wastewater, the latter can be treated effectively in the short term. However, most likely, the sludge bed will diminish with time. To re-establish the pelletised bed, the system will have to be switched back to wine wastewater for a period.

\section{Conclusions}

From the results obtained in this investigation the following conclusions could be made:

- When treating grain wastewater, a scum layer was formed on the liquid surface of the laboratory-scale UASB system, appearing as a thick gelatinous mass, covered by a thin crust. This confirmed that the problem identified at full scale could be reproduced at laboratory scale, validating the experimental protocol.

- The scum layer above was present with the grain wastewater in any form, i.e. blended with wine wastewater, or drum-filtered, settled or unsettled grain wastewater only. The scum-layer accumulation was most severe with unsettled grain wastewater, and reduced in the drum-filtered, blended and settled grain wastewater.

- With wine wastewater, scum-layer accumulation was not observed.

- The observations above indicate that scum-layer accumulation is a property of the grain wastewater, and not distillery wastewaters in general. Further, the scum-layer accumulation appears to be linked to the solids content of the grain wastewater. Reducing the solids content by drum filtration, settling or blending can reduce, but not eliminate, the scum-layer accumulation.

- The bed profiles measured for the UASB system treating wine wastewater conform to those measured previously with apple juice wastewater (Sam-Soon et al., 1987), glucose (Sam-Soon et al., 1990), protein (Moosbrugger et al., 1990), brewery wastewater (Moosbrugger et al., 1993a) and wine distillery wastewater (Moosbrugger et al., 1993b). In these profiles the typical three distinct zones of behaviour can be identified, namely lower active, upper active and upper inactive zones. The action of micro-organisms in these zones conforms to the proposals of Sam-Soon and co-workers (Wentzel et al., 1994).

- For the UASB system treating grain wastewater, the bed profile differs markedly from that above, in that the three zones of behaviour do not develop. A proposed explanation for this is the high suspended solids content of the grain wastewater. The rate of acidogenesis with suspended solids as substrate, would be limited by the rate of hydrolysis. Typically, hydrolysis rates are much slower than acidogenesis rates with a soluble substrate. The net effect is to lower the overall rate of acidogenesis. With the lower acidogenic rates, the short-chain fatty acids would be consumed in subsequent reactions as they are produced, with the result that the short-chain fatty acid concentrations would remain low throughout the UASB system. Also, the low rate of acidogenesis implies that the rate of $\mathrm{H}_{2}$ production is low so that a high $p \mathrm{H}_{2}$ zone does not develop in the sludge bed.

- The absence of the three distinct zones of behaviour with grain wastewater as influent raises the question of the long-term viability of a UASB system treating this type of wastewater. In developing their hypothesis for pelletisation in UASB systems, Sam-Soon et al. (1987) proposed that partial phase separation of the anaerobic processes and development of a zone with a high $\mathrm{pH}_{2}$ are essential for pellet formation (Wentzel et al., 1994). In the UASB system treating grain wastewater, observations (no HAc and little HPr) indicate that these prerequisites for pellet formation were not achieved. If this is true, according to the hypothesis of Sam-Soon et al. (1987) pellet growth will not occur, or it will be reduced greatly. This indicates that, in the long term in switching from wine wastewater (where pellet growth has occurred) to grain wastewater, there will be a gradual loss of the pelletised sludge bed, until it declines to such low values that the system will fail. This aspect requires confirmation from a long-term investigation with grain wastewater.

- The investigation indicates that when switching from wine wastewater, where a well-defined pelletised sludge bed has been developed, to grain wastewater, the grain wastewater can be treated effectively in the short term. However, as noted above, it is most likely that the sludge bed will diminish with time. To re-establish the pelletised bed, the system will have to be switched back to wine wastewater for a period.

\section{Acknowledgements}

This research was supported financially by the Stellenbosch Farmers' Winery, National Research Foundation and the University of Cape Town and is published with their permission.

\section{References}

BRITZ TJ (1998) Personal communication. Department of Food Science, University of Stellenbosch, South Africa.

BRITZ TJ, TRNOVEC W, VAN SCHALKWYK C and ROOS P (1999) Enhanced Granulation in Upflow Anaerobic Sludge-Bed Digesters (UASB) by Process Induction and Microbial Stimulation. WRC Report No 667/1/99.

DRIESSEN WJBM, TIELBAARD MH and VEREIJKEN TLFM (1994) Experience on anaerobic treatment of distillery effluent with the UASB process. Water Sci. Technol. 30 (12) 193-201.

FOURIE JM (1974) A Guide to the Treatment of Winery Effluent. CSIR Guide K18, 1-16.

LAUBSCHER ACJ, WENTZEL MC, LE ROUX JMW and EKAMA GA (2000) Operational Problems in a UASB System Treating Distillery Wastewaters. Research Report W104, Dept. Civil Eng., Univ. of Cape Town, Rondebosch 7701, South Africa.

LIN K and YANG Z (1991) Technical review on the UASB process. Int. J. Environ. Studies 39 203-222.

LOEWENTHAL RE, EKAMA GA and MARAIS GvR (1989) Mixed weak acid/base systems, Part I-Mixture characterisation. Water SA 15 (1) 3-24.

MCINERNEY MJ, BRYANT MP and STAFFORDDA (1979) In: Stafford DA, Wheatly BI and Hughes DE (eds.) Anaerobic Digestion. Applied Science Publishers Ltd., Ripple Road, Barking, Essex, England.

MOOSBRUGGER RE, LOEWENTHAL RE and MARAIS GvR (1990) Pelletisation in a UASB system with protein (casein) as substrate. Water SA 16 (3) 171-178.

MOOSBRUGGER RE, WENTZEL MC, EKAMA GA and MARAIS GVR (1992) Simple Titration Procedures to Determine $\mathrm{H}_{2} \mathrm{CO}_{3} *$ Alkalinity and Short Chain Fatty Acid Concentrations in Aqueous Solutions Containing Known Concentrations of Ammonium, Phosphate and Sulphide Weak Acid/Bases. WRC Report No. TT 57/92.

MOOSBRUGGER RE, WENTZEL MC, EKAMA GA and MARAIS GvR (1993a) Lauter tun (brewery) waste in UASB systems - Feasibility, alkalinity requirements and $\mathrm{pH}$ control. Water $S A 19$ (1) 41-52.

MOOSBRUGGER RE, WENTZEL MC, EKAMA GA and MARAIS GvR (1993b) Grape wine distillery waste in UASB systems - Feasibility, alkalinity requirements and pH control. Water SA 19 (1) 53-68.

SAM-SOON PALNS, LOEWENTHAL RE, DOLD PL and MARAIS GvR (1987) Hypothesis for pelletisation in the upflow anaerobic sludge bed reactor. Water SA 13 (2) 69-80. 
SAM-SOONPALNS, LOEWENTHAL RE, WENTZEL MC and MARAIS GvR(1989) Pelletization in the Upflow Anaerobic Sludge Bed(UASB) Reactor. Research Report W72, Dept. Civil Eng., Univ. of Cape Town, Rondebosch 7701, South Africa.

SAM-SOONPALNS, LOEWENTHALRE, WENTZEL MC and MARAIS GvR (1990) Growth of biopellets on glucose in upflow anaerobic sludge bed (UASB) systems. Water SA 16 (3) 151-164.
STANDARD METHODS (1985) Standard Methods for the Examination of Water and Wastewater (16 ${ }^{\text {th }}$ edn.) APHA, AWWA \& WPCF, New York.

SRK (Steffen Robertson and Kirsten) (1993) Water and Waste-Water Management in the Wine Industry. WRC Report No TT 51/90.

WENTZEL MC, MOOSBRUGGER RE, SAM-SOON PALNS, EKAMA GA and MARAIS GvR(1994) Tentative guidelines for waste selection, process design, operation and control of upflow anaerobic sludge bed reactors. Water Sci. Technol. 30 (12) 31-42. 